Article

\title{
Comparative Analysis of Four Facial Foundation Lotions with Reference to Its Antioxidant Richness and Bio-Safety
}

\author{
Mukesh Singh ${ }^{*}$, Pallavi Seth ${ }^{\dagger}$ and Shamayita Poddar ${ }^{\dagger}$ \\ Department of Biotechnology, Haldia Institute of Technology, HIT Campus, Purba Medinipur, \\ Haldia (West Bengal), Haldia 721657, India; pallaviseth24@gmail.com (P.S.); shamayitapoddar@gmail.com (S.P.) \\ * Correspondence: msingh006@gmail.com \\ t These authors contributed equally to this work.
}

Academic Editor: Enzo Berardesca

Received: 13 March 2017; Accepted: 28 April 2017; Published: 3 May 2017

\begin{abstract}
The market these days is a hub of a variety of commercially available cosmetic products, and foundation makeup to be precise, containing various types of important bioactive compounds both from natural and synthetic sources. The current study explores the usage of foundation lotions among undergraduate female students of an engineering college in West Bengal, India, and its antioxidant potential such as free radical scavenging, anti-lipid peroxidation, and reducing power. Red Blood Corpuscles hemolysis assay was also tested for evaluating it safety measures. Results confirmed the presence of antioxidant-related bioactive components and hence the antioxidant property in each brand tested, albeit in varying degrees. Free radical scavenging, anti-lipid peroxidation, and reducing power were also exhibited by all samples tested. Hemolytic activity was not significantly noted among the foundations, though each exhibited different results. Lotion with the least bioactive components exhibited high hemolytic activity. The findings of this study reveal the secret behind the usefulness of foundation lotions on the basis of antioxidant contents and free radical scavenging activity. The results of this study confirmed that it is very unlikely that all the essential qualities of a good cosmetic product will be present all at once.
\end{abstract}

Keywords: antioxidant capacity; chemical analysis; foundation lotions; free radicals; hemolysis; polyphenol; safety testing

\section{Introduction}

In every living organism, skin is an important external protective organ of the body. With ever-increasing lifestyles and increases in pollution loads, skin is the first to become affected, which results in aging, hyper-pigmentation, inflammation [1], and many more disorders such as skin cancer. The generation of free radicals, lipid peroxides, and harmful metabolites through several environmental factors leads to above-mentioned disorders [2]. These free radicals cause oxidative stress in the bodies of the living system.

To combat this issue, a variety of cosmetic products, and foundation makeup to be precise, containing various kinds of important bioactive compounds both from natural and synthetic sources, is commercially available. This wide range of cosmetics consists of products from different brands of companies, possessing different cost ranges that differ in quality. Increasing competition between the brands among themselves, with the increasing demand for these among the conscious youth these days, has resulted in an urge to test quality in terms of the antioxidant properties of these cosmetics.

Antioxidant is a compound that inhibits/scavenges free radical generation. Apart from natural sources, antioxidants, which are commonly used in food, cosmetics, and preservatives, are also 
being synthesized. The antioxidant activity of cosmetics is mainly correlated with their contents of polyphenols, proteins/peptides, Vitamins $\mathrm{C}$ and E, and a few metals such as selenium. Among these plant-derived antioxidants, polyphenols constitute a large and complex category of compounds [3]. Interest in the phenolic antioxidants in cosmetics has increased considerably because of their elevated capacity for scavenging free radicals and ROS (reactive oxygen species) associated with various diseases and ageing of skin tissues [4]. Studies have reported that polyphenols inhibit lipid peroxidation. Moreover, in vitro experimental data suggests that polyphenols and vitamins possess anti-inflammatory, anti-allergic, anti-viral, and anti-carcinogenic properties [5]. Antioxidant compounds are also known for their preservative property [6]. These biological properties are thought to be linked to the antioxidant activity of these compounds. Various herbs have long been used as antiseptics and cosmetics ingredients [7-11]. Facial foundations in different forms, including anhydrous cakes, emulsions, or powders, are available on the market. Foundation is prepared by adding colorants, moisturizer, photo-protectant, anti-aging agents, fragrances, and filling ingredients. The formulation is either based on completely synthetic chemicals, bioactive compounds, or mixture of both types. Each of these ingredients has important functions and acts cumulatively to impart benefits and user satisfaction.

The objective of this study was to conduct a short survey on the usage of foundation lotions among young girls and to correlate its antioxidant potential with cost. The selection of the cosmetic was done by a survey conducted among a group of 200 girls aged between 19 and 23 years, all of whom were undergraduate students of an engineering college in West Bengal, India, to find out which foundation lotion was more popular among the students. According to this study, we narrowed it down to four top brands, conducted various in vitro assays associated with antioxidants and safety tests, and drew a conclusion based on their quality and performance.

\section{Materials and Methods}

\subsection{Materials}

The foundation lotions chosen as a result of the survey conducted, comprised of four well-known brands, coded as F1, F2, F3 and F4. They were bought in bottles of $100 \mathrm{~mL}$ and stored at room temperature for further experiments. For commercial reasons, the actual names of the brands are not disclosed. All chemicals used for experimental assays were of analytical grade and purchased from Sigma, Merck, and Himedia.

\subsection{Preparation of Cosmetic Ethanol-Water Extract}

Stock solutions of each foundation were prepared by making $10 \%$ solution in a mixture of ethanol-water (70:30). The suspensions of each foundation in the solvent system were incubated for $30 \mathrm{~min}$ with periodical shaking. After the incubation period was complete, the solutions were centrifuged at $5000 \mathrm{rpm}$ for $10 \mathrm{~min}$ at room temperature. Post-centrifugation, the supernatant containing the foundation extract was filtered using Whatman filter paper. The clear solvent extract of each foundation were collected in amber colored glass bottles and stored in a refrigerator for further use.

\subsection{Determination of Total Protein}

Lowry's method was followed for the determination of total protein/peptides contained in the cosmetics [12].

\subsection{Determination of Phenol}

The polyphenolic content of the cosmetic extract was quantified by Folin-Ciocalteu method with a minor modification [13]. In brief, $100 \mu \mathrm{L}$ of cosmetic extract was added to $1 \mathrm{~mL}$ of distilled water, followed by $0.5 \mathrm{~mL}$ of Folin-Ciocalteu reagent. The mixture was briskly shaken and was kept at room 
temperature for $3 \mathrm{~min}$. After the incubation was complete, $1 \mathrm{~mL}$ of $20 \% \mathrm{Na}_{2} \mathrm{CO}_{3}$ was added to each set. The mixture was again shaken briefly and was heated for $1 \mathrm{~min}$ in an incubator at $95^{\circ} \mathrm{C}$ and was allowed to cool at room temperature. The absorbance was recorded at $765 \mathrm{~nm}$ using an UV-Vis spectrophotometer (ShimadzuUV-1700, Kyoto, Japan) and was expressed as gallic acid equivalents (GAE) per gm of cosmetic product.

\subsection{Total Antioxidants Capacity}

An assay based on the reduction of molybdenum (VI) to molybdenum (V) by the cosmetic extract and the subsequent formation of a green solution was followed for the determination of total antioxidant capacity [14]. In brief, in a screw-capped tube, $100 \mu \mathrm{L}$ of extract was pooled and mixed with $1 \mathrm{~mL}$ of reagent solution ( $0.6 \mathrm{M}$ sulfuric acid, $28 \mathrm{mM}$ sodium phosphate, and $4 \mathrm{mM}$ ammonium molybdate). The tubes were incubated at $95{ }^{\circ} \mathrm{C}$ for $90 \mathrm{~min}$, followed by a cooling of the sample to room temperature. The optical density was measured at $695 \mathrm{~nm}$ against the blank $(1 \mathrm{~mL}$ of reagent solution along with the appropriate volume of water) and was expressed as the equivalents of ascorbic acid.

\subsection{Free Radical Scavenging Activity Using DPPH}

Free radical scavenging potential of the cosmetic extract was measured on the basis of eradications of DPPH-generated free radicals [15]. Briefly, a $5 \mathrm{~mL}$ reaction mixture consisted of $1 \mathrm{~mL}$ of cosmetic extract and $4 \mathrm{~mL}$ of a $0.1 \mathrm{mM}$ methanolic DPPH solution. The control set contained $1 \mathrm{~mL}$ of methanol and $4 \mathrm{~mL}$ of the DPPH solution. The tube containing the reaction mixture was thoroughly mixed and incubated for $30 \mathrm{~min}$ at room temperature. The change in absorbance at $517 \mathrm{~nm}$ of the samples was recorded. Inhibition concentration of lotion extract in $50 \%\left(\mathrm{IC}_{50}\right)$ was determined. Radical scavenging activity was expressed as the inhibition percentage calculated using the following formula:

$$
\text { percentage inhibition activity }=[(\mathrm{A}-\mathrm{B}) / \mathrm{A})] \times 100
$$

where $\mathrm{A}=$ absorbance of the blank solution, and $\mathrm{B}=$ absorbance of the test solution.

\subsection{Anti-Lipid Peroxidation Effect}

Anti-lipid peroxidation activity of extract of foundation lotions was done according to the thio-barbituric acid-reactive species (TBARS) assay with minor modification [16] using goat liver homogenate. Homogenate $(10 \% w / v)$ in a $0.1 \mathrm{M}$ phosphate buffer $(\mathrm{pH} 7.0)$ was prepared with a fresh goat liver in a cold condition. The homogenate was centrifuged at $8000 \mathrm{rpm}$ for $10 \mathrm{~min}$. After the centrifugation, the clear supernatant was collected and used for the study of lipid peroxidation. Different volumes of cosmetic extract of each lotion were taken in screw-capped tubes. Liver homogenate $(0.5 \mathrm{~mL})$ were added to all test tubes. The total volume was adjusted to $1 \mathrm{~mL}$ by double-distilled water. $\mathrm{FeSO}_{4}(0.07 \mathrm{M})$ was added to each test tube for the initiation of peroxidation and incubated for $30 \mathrm{~min}$ at $37^{\circ} \mathrm{C}$. Then, $20 \%$ acetic acid $(1.5 \mathrm{~mL}), 0.8 \%$ TBA in $1.1 \%$ SDS (1.5 mL), and ice chilled $20 \%$ TCA $(50 \mu \mathrm{L})$ were added to all test tubes and were gently vortexed. The reaction mixtures were heated at $95{ }^{\circ} \mathrm{C}$ for $1 \mathrm{~h}$. After the incubation was complete, samples were cooled, and $5 \mathrm{~mL}$ of $\mathrm{n}$-butanol were added to each tube. The whole set was centrifuged at $300 \mathrm{rpm}$ for $10 \mathrm{~min}$ and an organic layer was removed and placed into a fresh tube. The absorbance of the organic layer was measured at $532 \mathrm{~nm}$. A similar experimental set was prepared in the absence of extract and was used as a control. The inhibition concentration of the lotion extract in 50\% (IC50) was determined.

Anti-lipid peroxidation (ALPO) was calculated by using the formula

$$
\mathrm{ALPO} \%=1-(\mathrm{E} / \mathrm{C}) \times 100
$$

where $\mathrm{E}$ is the absorbance of sample, and $\mathrm{C}$ is the absorbance of the blank. 


\subsection{Ferric Reducing Antioxidant Power (FRAP)}

The reducing power of the extracts was evaluated following the method of Oyaizu [17]. Briefly, 10-1000 $\mu \mathrm{L}$ of cosmetic ethanol extract in a total volume of $1 \mathrm{~mL}$ were mixed with $2.5 \mathrm{~mL}$ of phosphate buffer $(0.2 \mathrm{M}, \mathrm{pH} 6.6)$ and $2.5 \mathrm{~mL}$ of potassium ferricyanide (1\%). The reaction mixture was incubated at $50{ }^{\circ} \mathrm{C}$ for $30 \mathrm{~min}$. Thereafter, $2.5 \mathrm{~mL}$ of trichloroacetic acid $(10 \%)$ was added to the reaction mixture and gently mixed followed by centrifugation at $3000 \mathrm{rpm}$ for $10 \mathrm{~min}$. Finally, $2.5 \mathrm{~mL}$ of the upper layer from the reaction mixture was added to $2.5 \mathrm{~mL}$ of distilled water and $0.5 \mathrm{~mL}$ of $0.1 \%$ ferric chloride. Absorbance at $700 \mathrm{~nm}$ was measured. The increase in the absorbance at $700 \mathrm{~nm}$ indicated an increase in the reducing power of the extracts. The inhibition concentration of the lotion extract in $50 \%$ (IC50) was determined.

\subsection{Metal Chelating Effect}

To evaluate metal chelating property of the test samples, $200 \mu \mathrm{L}$ of the respective samples were mixed with $800 \mu \mathrm{L}$ of distilled water; to this, $50 \mu \mathrm{L}$ of $\mathrm{FeCl}_{2}(2 \mathrm{mM})$ and $50 \mu \mathrm{L}$ of ferrozine $(5 \mathrm{mM})$ were added [18]. The reaction mixture was mixed gently and stored for $10 \mathrm{~min}$. After the incubation was complete, the respective color change was observed at $550 \mathrm{~nm}$. The inhibition concentration of the lotion extract in 50\% (IC50) was determined.

\subsection{Anti-Hemolytic Activity}

The hemolytic assay was performed based on Goswami et al. [19] using fresh human blood procured from a local pathology center. Here, $0.1 \%$ Triton X-100 was used as a positive control. Briefly, fresh erythrocytes $(10 \%$ in PBS pH 7.4) were treated with different concentrations of test samples for $1 \mathrm{~h}$ at $37^{\circ} \mathrm{C}$. Triton X-100 (0.1\%) and PBS were used as positive and negative controls, respectively. After the completion of the incubation period, the erythrocytes were harvested and the supernatant of each sample was collected into fresh Eppendorf tubes. Absorbance of the supernatant was measured at $540 \mathrm{~nm}$. The hemolysis percentage was determined by the following equation:

$$
\% \text { Hemolysis }=[(\mathrm{AT}-\mathrm{AC}) /(\mathrm{A} 100 \%-\mathrm{AC})] \times 100
$$

where AT is the absorbance of the supernatant from samples incubated with the test samples; AC is the absorbance of the supernatant from controls (normal saline); A $100 \%$ is the absorbance of the supernatant of positive controls incubated in the presence of $0.1 \%$ Triton X-100, which causes complete lysis of Red Blood Corpuscles.

\subsection{Statistical Analysis}

Each experiment was conducted at least three times. Results were reported as mean \pm standard deviation. The results were analyzed using ANOVA and subjected to a least significant difference (LSD) for the item comparisons wherever it is applicable.

\section{Results and Discussions}

\subsection{Survey Reports}

The selection of facial cosmetics was made based on the results of a survey conducted among a group of 200 girls aged between 19 and 23 years, all undergraduate students of an engineering college in West Bengal, India, in order to find out which foundation lotion was more prevalent among the female students. We narrowed it down to four top brands foundation lotions based on usage and user compliance. The foundation lotions thus chosen were coded as F1, F2, F3, and F4 for commercial reasons. Figure 1 shows the percentage of usage of the four chosen lotions among students surveyed. The important questionnaires of the survey were brand name, cost, side effects, and satisfaction, i.e., 
value for money (Supplementary Material 1). Foundation Lotion F1 was found to be more prevalent $(60 \%)$ followed by F2, F3, and F4.

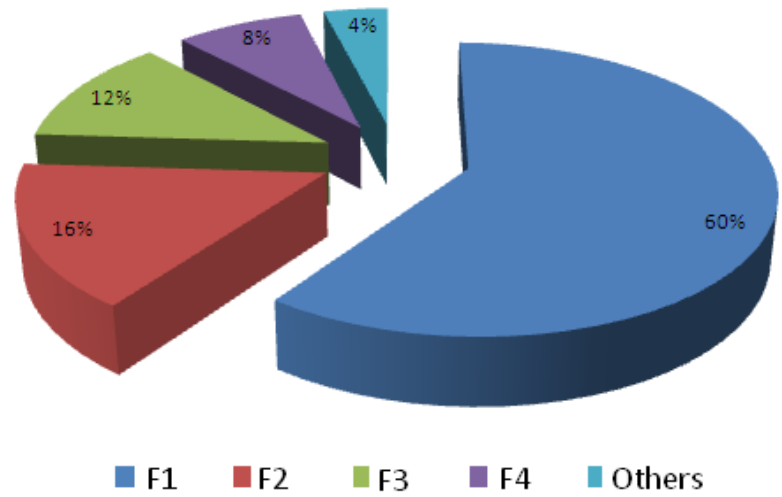

Figure 1. The percentage usage of foundation lotions of various brands among a group of undergraduate female students of an engineering college at West Bengal, India. Population size was 200, age group 19-23 years. The selected cosmetics were abbreviated as F1-F4.

\subsection{Bioactive Components in the Foundation Lotion}

Biochemical analysis of the ethanol extracts of each foundation was carried out for the presence of proteins/peptides and polyphenol content; the results indicated that the samples had significant amounts of these components though in varying amounts (Table 1). F1 contained the least protein when compared to the other three. F2, F3, and F4 demonstrated significantly high protein content. Peptide-based cosmetics are in high demand due to many beneficial properties such as antimicrobial, anti-inflammatory, anti-aging, and UV-protection [10]. Polyphenols are one of the most important compounds exhibiting a high degree of antioxidant and other important properties. Analysis of the samples indicated a high phenolic content in F3 and F4, followed by F2 and F1 (Table 1). Analysis of the samples for total antioxidant capacity indicates the presence of antioxidants in each of the foundations, although in different degrees. Antioxidants in high amount were observed in F3 followed by F4, F2, and F1 (Table 1). The total antioxidant content of foundation extracts is significant for F2, F3, and F4 when compared with F1, but F2, F3, and F4 are non-significant $(P \leq 0.05)$ when compared among themselves. Here, the result of total polyphenol corroborates with antioxidant capacity. Phenolic compounds have been reported to contain antimicrobial properties besides antioxidant activities; the higher phenolic content is an indicative measure of both of these. Generally, in cosmetic products, chemical preservatives are added to enhance shelf life. Presently, with the wide acceptance of herbal products, naturally obtained phenolic compounds are used as preservatives due to their antimicrobial properties coupled with free radical scavenging activity. Apart from phenolic compounds, proteins/peptides are also used in cosmetics as anti-aging agents. A number of plant-derived bioactive components and well-researched synthetic chemicals are being used as anti-aging agents in most facial creams and lotions [20-23].

Table 1. Quantitative analysis of bioactive components and total antioxidant capacity of ethanol extract of four facial foundation lotions. Results are represented as mean \pm standard deviation of three independent experiments.

\begin{tabular}{ccccc}
\hline \multirow{2}{*}{ Items } & \multicolumn{4}{c}{ Foundation Lotions } \\
\cline { 2 - 5 } & F1 & F2 & F3 & F4 \\
\hline Protein $(\mu \mathrm{g} / \mathrm{mL}$ eq BSA) & $0.023 \pm 0.001$ & $0.484 \pm 0.07$ & $0.531 \pm 0.02$ & $0.598 \pm 0.3$ \\
Polyphenol $(\mu \mathrm{g} / \mathrm{mL}$ eq $\mathrm{GA})$ & $82.500 \pm 3.53$ & $158.500 \pm 12.02$ & $500 \pm 12.02$ & $256.500 \pm 9.19$ \\
Total Antioxidant Capacity $(\mu \mathrm{g} / \mathrm{mL})$ & $6.250 \pm 0.35$ & $12.150 \pm 0.91$ & $13.000 \pm 0.70$ & $12.200 \pm 0.99$ \\
\hline
\end{tabular}




\subsubsection{Antioxidant Study}

Analysis of the foundation extracts, for free radical scavenging (here di(phenyl)-(2,4,6-trinitrophenyl)iminoazanium DPPH scavenging), anti-lipid peroxidation, metal chelating, and reducing potential demonstrated all of these properties in the samples in significantly good amounts. Table 2 shows DPPH scavenging activity of the foundation lotions, where F1 and F2 show better results than F3 and F4. Scavenging the free radicals is thus beneficial, as these radicals tend to oxidize proteins, lipids, and DNA, giving rise to aging and other related oxidative stresses [24]. Cosmetics with high antioxidant also inhibit microbial growth on skin. Antioxidant compounds isolated from fruit peels showed high antimicrobial activity against many dreadful microorganisms [25]. The reducing property measures the electron-donating capacity of an antioxidant. Our result demonstrates an increase in the reducing potential of Test Samples F1, F3, and F4, respectively (Table 2). Studying the metal chelating activities of the four lotions, F3 showed the highest chelating capacity followed by F1, F4, and F2, respectively. The presence of transition metal ions induces free radical generation via Fenton reaction, which enhances lipid per oxidation and protein breakdown in skin. We also studied the anti-lipid peroxidation potential of foundation extracts. Results indicate good inhibition of lipid peroxidation of lipids in goat liver homogenate. Table 2 shows almost equal activities in the four samples. Though F1 exhibited low protein and polyphenol contents but have high potential in scavenging free radicals, Foundation F1 might have synthetic antioxidant compounds similar to butylated hydroxytoluene (BHT) and others.

Table 2. Comparison of IC50 of ethanol extract of four facial foundation lotions in relation to antioxidant potential. IC50 value is expressed in $\mu \mathrm{g} / \mathrm{mL}$. Results are represented as mean \pm standard deviation of three independent experiments.

\begin{tabular}{ccccc}
\hline \multirow{2}{*}{ Items } & \multicolumn{4}{c}{ Foundation Lotions } \\
\cline { 2 - 5 } & F1 & F2 & F3 & F4 \\
\hline DPPH & $12.5 \pm 0.70$ & $10.75 \pm 1.00$ & $8.40 \pm 0.78$ & $9.45 \pm 1.50$ \\
Reducing Property & $111.5 \pm 4.94$ & 0 & $130 \pm 7.07$ & $78.75 \pm 3.89$ \\
Lipid Peroxidation & $253.5 \pm 4.94$ & $256 \pm 8.48$ & $257.85 \pm 11.1$ & $260.1 \pm 14.28$ \\
Metal Chelating & $36.85 \pm 2.47$ & $41.9 \pm 2.68$ & $25.45 \pm 0.63$ & $36.85 \pm 2.61$ \\
\hline
\end{tabular}

\subsubsection{Anti-Hemolytic Activity}

The safety evaluation is an important step in the assessment of any pharmaceuticals products, cosmetics and food items for human consumption. In vitro assays will help in the evaluation of biocompatibility of drugs and cosmetics due to recent regulations in the protection of experimental animals [26]. The RBC hemolysis assay is an easy and quick method to evaluate the bio-safety of chemicals or formulations. This study also helps us to screen nontoxic formulations. The hemolytic behavior of foundation extract on human blood was determined by incubating the reaction mixture at $37^{\circ} \mathrm{C}$ for $1 \mathrm{~h}$. Analysis of the ethanol extract of the foundation lotions on human RBC demonstrated interesting results. F1 exhibited very high hemolytic behavior compared to the other three, which showed moderate hemolysis of red blood cells (Figure 2). This may be due to synthetic antioxidants in Formulation F1. As was reported earlier, synthetic compounds have adverse effects on our cells. The proportion of plant-derived polyphenols is lower compared to the other three formulations. Triton $\mathrm{X}-100(0.1 \%)$ was used as positive control. Bio-safety evaluations using hemolysis assays have been widely reported [27]. 


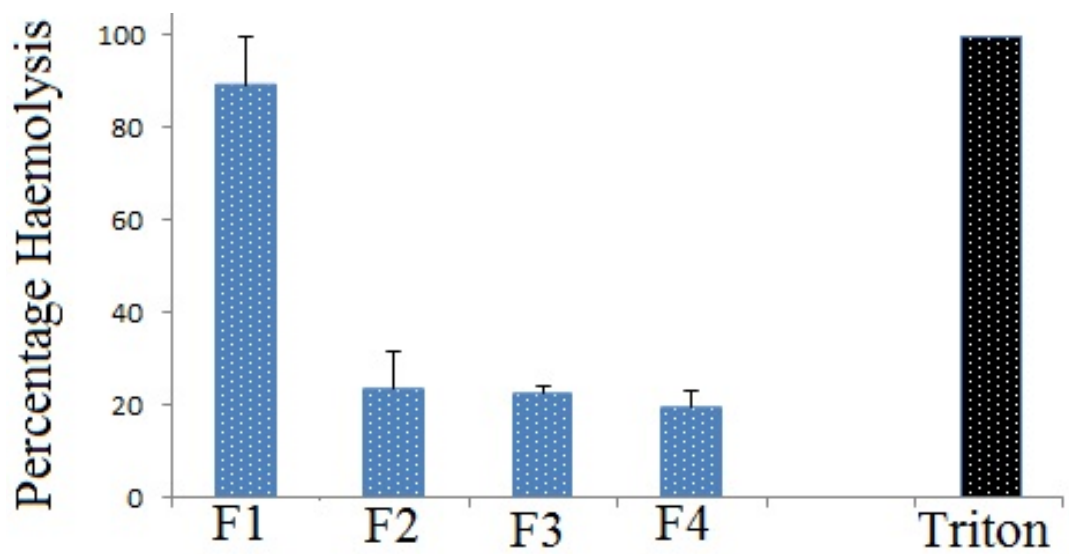

Figure 2. Hemolytic action of ethanol extract of foundation lotion on human Red Blood Corpuscles. Here, Triton X-100 was considered as positive control.

A comparative analysis of all the results show that facial foundation lotions F2, F3 and F4 exhibited high antioxidant content, which is synonymous to the phenolic content [13]. Protein content and anti-lipid peroxidation activity are also observed to be high in F2, F3 and F4. Metal chelating activity is seen to be the highest in cosmetic F3, followed by F1, F4 and F2. In contrast, the reducing power and the hemolytic activity are seen to be the lowest in cosmetic F3 followed by F4. Though F1 contains comparatively less proteins, phenols and antioxidant capacity, but demonstrates high free radical scavenging, reducing, anti-lipid potential and metal chelating activities. The results indicate that foundation F1 might have chemical ingredients behaving like strong antioxidants. Strong hemolytic activity also indicates the same. Thus, Cosmetic Products F3 and F4 show a very stable behavior, indicating a presence of useful molecules and a lower amount of harmful and damaging chemicals. Market studies have showed that they are low cost, hence economical to a great extent.

\section{Conclusions}

The results of this study show that it is very unlikely that all the essential qualities of good cosmetics will be present together in one product. The cost of the products plays a major role here, thereby showing that even low-cost makeup might contain some of the beneficial properties that might not be present in high-priced makeup. Hence, buying costly makeup does not always guarantee that it is best for the human skin. Thorough biochemical assays by different methods help us reveal the secret behind the usefulness of these products, but a detailed insight into this study is needed to obtain more accurate and better results.

Supplementary Materials: The following are available online at www.mdpi.com/2079-9284/4/2/12/s1: File 1: Survey Questionnaires.

Acknowledgments: The authors would like to thank Pranab Roy for his help during the manuscript preparation. The authors would also like to acknowledge the local pathology center and all the participants who were part of our survey work.

Author Contributions: M.S. conceived and designed the experiments; P.S. and S.P. performed the experiments; all three authors analyzed the data.

Conflicts of Interest: The authors declare no conflict of interest.

\section{References}

1. Benedetto, A.D.; Agnihothri, R.; McGirt, L.Y.; Bankova, L.G.; Beck, L.A. Atopic dermatitis: A disease caused by innate immune defects? J. Investig. Dermatol. 2009, 129, 14-30. [CrossRef] [PubMed]

2. Narayanaswamy, N.; Balakrishnan, K.P. Evaluation of some medicinal plants for their antioxidant properties. Int. J. Pharm Tech. Res. 2011, 3, 381-385. 
3. Benzie, I.F.F. Evolution of dietary antioxidants. Comp. Biochem. Physiol A Mol. Integr. Physiol. 2003, 136, 113-126. [CrossRef]

4. Epstein, H. Cosmeceuticals and polyphenols. Clin. Dermatol. 2009, 275, 475-488. [CrossRef] [PubMed]

5. Boudjou, S.; Oomah, B.D.; Zaidi, F.; Hosseinian, F. Phenolics content and antioxidant and anti-inflammatory activities of legume fractions. Food Chem. 2013, 138, 1543-1550. [CrossRef] [PubMed]

6. Kabara, J.J.; Orth, D.S. Preservative-Free and Self-Preserving Cosmetics and Drugs: Principles and Practices; CRC Press: Boca Raton, FL, USA, 1997.

7. Wang, K.H.; Lin, R.D.; Hsu, F.L.; Huang, Y.H.; Chang, H.C.; Huang, C.Y.; Lee, M.H. Cosmetic applications of selected traditional Chinese herbal medicines. J. Ethnopharmacol. 2006, 106, 353-359. [CrossRef] [PubMed]

8. Msaada, K.; Salem, N.; Bachrouch, O.; Bousselmi, S.; Tammar, S.; Alfaify, A.; Sane, K.L.; Ammar, W.B.; Azeiz, S.; Brahim, A.H.; et al. Chemical composition and antioxidant and antimicrobial activities of wormwood (Artemisia absinthium L.) essential oils and phenolics. J. Chem. 2015, 2015, 1-12. [CrossRef]

9. Ribeiro, A.S.; Estanqueiro, M.; Oliveira, M.B.; Lobo, J.M.S. Main benefits and applicability of plant extracts in skin care products. Cosmetics 2015, 2, 48-65. [CrossRef]

10. Saewan, N.; Jimtaisong, A. Natural products as photoprotection. J. Cosmet. Dermatol. 2015, 14, 47-63. [CrossRef] [PubMed]

11. Khan, B.A.; Akhtar, N.; Menaa, B.; Menaa, B.; Braga, B.A.; Menaa, F. Relative free radicals scavenging and enzymatic activities of Hippophae rhamnoides and Cassia fistula extracts: Importance for cosmetic, food and medicinal applications. Cosmetics 2017, 4, 3. [CrossRef]

12. Lowry, O.H.; Rosebrough, N.J.; Farr, A.L.; Randall, R.J. Protein measurement with the folin phenol reagent. J. Biol. Chem. 1951, 193, 265-275. [PubMed]

13. Slinkard, K.; Singleton, V.L. Total phenol analysis: Automation and comparison with manual methods. Am. J. Enol. Viticult. 1977, 28, 49-55.

14. Cao, G.; Prior, R.L. Measurement of total antioxidant capacity in nutritional and clinical studies. In Handbook of Antioxidants; Cadenas, E., Packer, L., Eds.; CRC Press: Boca Raton, FL, USA, 2001; pp. 47-55.

15. Sanchez-Moreno, C.; Jimenez-Escrig, A.; Saura-Calixto, F. Study of low-density lipoprotein oxidizability indexes to measure the antioxidant activity of dietary polyphenols. Nutr. Res. 2000, 20, 941-953. [CrossRef]

16. Janero, D.R. Malondialdehyde and thiobarbituric acid-reactivity as diagnostic indices of lipid peroxidation and peroxidative tissue injury. Free Radic. Biol. Med. 1990, 9, 515-540. [CrossRef]

17. Oyaizu, M. Studies on product of browning reaction prepared from glucose amine. Jpn. J. Nutr. 1986, 7, 307-315. [CrossRef]

18. Dinis, T.C.P.; Madeira, V.M.C.; Almeida, M.L.M. Action of phenolic derivates (acetoaminophen, salycilate and 5-aminosalycilate) as inhibitors of membrane lipid peroxidation and as peroxyl radical scavengers. Arch. Biochem. Biophys. 1994, 315, 161-169. [CrossRef] [PubMed]

19. Goswami, S.R.; Sahareen, T.; Singh, M.; Kumar, S. Role of biogenic silver nanoparticles in disruption of cell-cell adhesion in Staphylococcus aureus and Escherichia coli biofilm. J. Ind. Eng. Chem. 2015, 26, 73-80. [CrossRef]

20. Draelos, Z.D. The Multifunctional Value of Sunscreen containing Cosmetics. Skin Ther. Lett. 2011, 16, 1-3.

21. Serpone, N.; Dondi, D.; Albini, A. Inorganic and organic UV filters: Their role and efficacy in sunscreens and suncare products. Inorg. Chim. Acta 2007, 360, 794-802. [CrossRef]

22. Khan, B.A.; Akhtar, N.; Menaa, A.; Menaa, F. A novel Cassia fistula (L.)-based emulsion elicits skin anti-aging benefits in humans. Cosmetics 2015, 2, 368-383. [CrossRef]

23. Sharif, A.; Akhtar, N.; Khan, M.S.; Menaa, A.; Menaa, B.; Khan, B.A.; Menaa, F. Formulation and evaluation on human skin of a water-in-oil emulsion containing Muscat hamburg black grape seed extract. Int. J. Cosmet. Sci. 2015, 37, 253-258. [CrossRef] [PubMed]

24. Bouftira, I.; Abdelly, C.; Sfar, S. Characterization of cosmetic cream with Mesembryanthemum crystallinum plant extract: Influence of formulation composition on physical stability and antioxidant activity. Int. J. Cosmet. Sci. 2008, 30, 443-452. [CrossRef] [PubMed]

25. Joshi, V.K.; Kumar, A.; Kumar, V. Antimicrobial, antioxidant and phyto-chemicals from fruit and vegetable wastes: A review. Int. J. Food Ferment. Technol. 2012, 2, 123-136.

26. Corsini, E.; Papale, A.; Galbiati, G.; Roggen, E.L. Safety evaluation of cosmetic ingredients: In vitro opportunities for the identification of contact allergens. Cosmetics 2014, 1, 61-74. [CrossRef] 
27. Hans, R.K.; Agrawal, N.; Verma, K.; Misra, R.B.; Ray, R.S.; Farooq, M. Assessment of the phototoxic potential of cosmetic products. Food Chem. Toxicol. 2008, 46, 1653-1658. [CrossRef] [PubMed] 